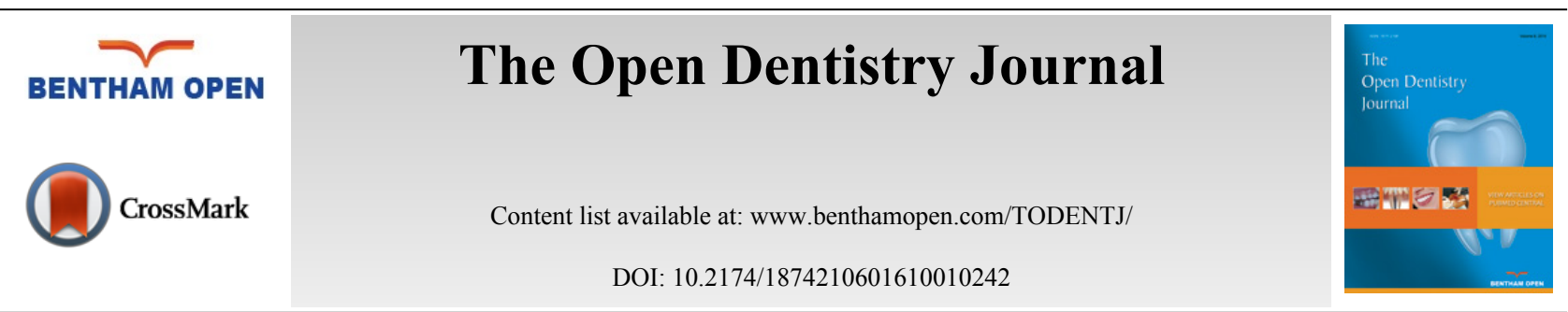

\title{
Clinical and Spectrophotometric Evaluation of LED and Laser Activated Teeth Bleaching
}

\author{
R. Lo Giudice ${ }^{1}$, G. Pantaleo ${ }^{2}$, A. Lizio ${ }^{1}$, U. Romeo ${ }^{3}$, G. Castiello², G. Spagnuolo,* and G. Lo \\ Giudice $^{1}$ \\ ${ }^{1}$ Medical Sciences and Stomatology Department, School of Dentistry, University of Messina, Messina, Italy \\ ${ }^{2}$ Department of Neurosciences, Reproductive and Odontostomatological Sciences, University of Naples Federico II, \\ Naples, Italy \\ ${ }^{3}$ Department of Oral and Maxillofacial Sciences University Sapienza, Rome, Italy
}

\section{Abstract:}

Background:

Auxiliary power sources (LED and laser) are used in in-office teeth bleaching techniques to accelerate the redox reaction of the whitening gel to increase ease of use, to improve comfort and safety, and to decrease the procedure time.

\section{Objective:}

The aim this study is to evaluate the efficiency of the teeth whitening procedures performed with hydrogen peroxide and carbamide peroxide, LED or Laser activated.

\section{Method:}

18 patients, affected by exogenous dyschromia, were treated with a bleaching agent composed by $35 \%$ hydrogen peroxide and $10 \%$ carbamide peroxide. They were divided into two groups: in the first group the bleaching agent was activated by a LED lamp; in the second group it was activated by a Laser diode lamp. Both groups were subjected to 3 bleaching cycle of 15 ' each. The chromatic evaluations were performed before and after one week from the treatment, using a chromatic scale and a spectrophotometer. The mean value of pre, post bleaching and follow-up were analyzed using a T-test, with results statistically significant for $\mathrm{P}<0,05$.

\section{Results:}

Results showed that the variations in brightness, chroma and hue are significantly influenced by the interaction between the whitening agent and the original colour of the teeth. Laser-activation has marginally improved the bleaching effectiveness. All patients treated with laser activation complained an increase in dental sensitivity.

\section{Conclusion:}

The use of laser-activating systems did not improve the efficacy of bleaching.

Keywords: Anchorage, Bleaching, Carbamide peroxide, Hydrogen peroxide, Laser, LED, Spectrophotometer.

\section{INTRODUCTION}

A correct treatment plan that lead to the correction of the tooth color must be based on the evaluation of the dyschromia grade, etiology based (Table 1), which is mandatory to determine the type of treatment and state about the

\footnotetext{
* Address correspondence to this author at the Department of Neurosciences, Reproductive and Odontostomatological Sciences, University of Naples Federico II, Naples, Italy; Tel/Fax: +390817462080; E-mails: gspagnuo@unina.it, gianrico.spagnuolo@gmail.com
} 
long term predictability and long term stability results [1].

Even if, today there are several diagnostic methods for performing the better treatment choice in the teeth color, shape and structure evaluation like FEM investigations or Computer systems, the first clinical view still remains the treatment of choice [2 - 4].

The tooth, change theirs colors, due to morphostructural modification age induced. Life style, food and beverage consumption, smoke, oro-dental pathologies, and some drug treatment, may concurs to chromatic modification that are peculiar, because linked both to constitutional and genetic factors [5 - 9].

The main chemical agents used in dentistry for the chemical teeth bleaching of the endogenous dyschromia are oxygen peroxide and carbammide peroxide [10].

The action mechanism is linked to their penetration capacity and to the release of oxygen free radicals in the teeth structure [11].

Table 1. Discoloration classification.

\begin{tabular}{|l|c|c|}
\hline \multicolumn{1}{|c|}{ ESOGENOUS DYSCHROMIA } & \multicolumn{2}{c|}{ ENDOGENOUS DYSCHROMIA } \\
\cline { 2 - 3 } & PRE-ERUPTIVE & POST-ERUPTIVE \\
\hline Chromophorous bacteria (actinomicetes) & Imperfect dentinogenesis & Decalcification \\
\hline Food and beverages (tea, coffee, wine, coca-cola e liquorice) & Imperfect amelogenesis & Carious lesion \\
\hline Mouthwash (Clorexidine) & Dentinal dysplasia & Enamel erosion \\
\hline Drugs & Hyperbilirubinemia & Restoration matherials \\
\hline Stannous florure & Phenylchetonuria & Dental traumas \\
\hline Plaque, tartarum & Haematic diseases & Endodontic treatment \\
\hline Smoke & Endocrine diseases & \\
\hline Heavy metal salt & Dental fluorosis & \\
\hline & Tetracycline dischromia & \\
\hline
\end{tabular}

The chemical reaction, on oxido-reduction, determines the saturation or the substitution of the double link in the cromogenous substances that will convert into incolor low molecular weight compound.

The so obtained variation of the coronal enamel and dentin, modality of light absorbance and reflection, determines the bleaching effect [11].

As for all the mdical procedures the bleaching may determine some complication, linked to the chemical reaction and the inducted increased permeability in the dental tissue.

The $38 \%$ hydrogen peroxide, showed strong oxidant effects that may damage the enamel.

The urea separation reaction, that is a compound included in the $35 \%$ carbammide peroxide, into carbonium dioxide and ammoniac, may cause structural degradation of the interprismatica proteins as amelogenine.

The enamel and dentin modified permeability, may cause an increased dentinal sensibility that may occurs in few minutes $[12,13]$.

The symptomatology is commonly resolved after two or three days, but may be prolonged and evolve in reversible pulpitis, characterized by pain, localized in one or more teeth, that can be evoked by different type of stimulation (thermal, chemical or osmotic) [14].

Moreover, the dentinal substratum modification determines the necessity of delaying for some days the adhesive restoration due to the substantial lowering of the bonding capacity of adhesion [15 - 17].

Marginal periodontitis may occasionally be present due to the contact between the gel and the mucosa; this are shown as edema and rarely ulceration. The use of rubber dam or gingival protection lower this kind of complication.

The technique used in bleaching treatment may be distinguished in: home and professional bleaching.

When professional bleaching is performed the efficiency of the carbamide peroxide can be increased up to $30 \%$, thanks to the use of photoactivation devices that improve the effects and penetration of the compound.

Light emission could be achieved using different type of lamps (Halogen, plasma, ultraviolet, laser and LED) that allows clinician use a lower concentration of bleaching gel and less application. 
The association between diode laser, that works on a wave length of $810 \mathrm{~nm}$, and a chromophore light blue/blue added into the bleaching gel, showed an increased efficiency and allows an adequate control [16].

But the small area irradiated dimension of the laser beam limit its use on both the maxillary and mandibular teeth at the same time, doubling the time required for the treatment.

The LED lamp are characterized by a uniform wave length and are provided with filter that lower the increasing of pulp temperature [16].

This mechanism is connected to a generalized heat production the speed-up the oxide-reduction reaction acting on the activator (iron-hydroxide) increasing the oxygen free radicals release.

Moreover, an excessive heat could determine some negative effects on pulp, as hyperthermia or inflammatory pulpitis that are caused by bleaching agent penetration in the pulp chamber and periodontitis due to the contact between gel and periodontal through the radicular dentin and radicular apex [18].

The aim of this study was to evaluate clinically and instrumentally (using a spectrophotometer), the efficiency of the teeth whitening procedures performed with hydrogen-peroxide and carbamide peroxide, LED or Laser activated.

\section{MATERIALS AND METHOD}

18 Subjects, affected by exogenous dyschromia, was treated with a bleaching agent composed by $35 \%$ hydrogen peroxide and $10 \%$ carbamide peroxide (Opalescence Boost, Ultradent).

The patients that to the physical or instrumental examination showed the presence of enamel infraction, esthetical reconstruction, gingival recession, referred dentinal hypersensivity or has been already subjected to teeth bleaching procedures, were excluded.

All patients, before the bleaching treatment, were submitted to a full mouth professional debridement. After liquid dam positioning, the patients, were subjected in a single clinical time to the same combination of bleaching agent (Figs. 1, 2).

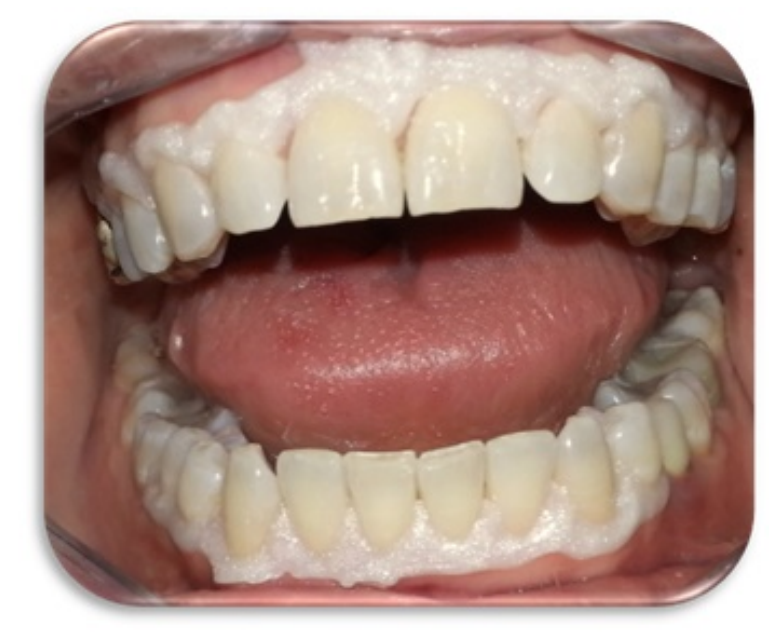

Fig. (1). Clinical phase: application of liquid dam to protect soft tissues.

In 9 patients, the bleaching treatment was performed using a LED lamp (WS25-Kroma Ogna ${ }^{\mathrm{TM}}$ ) composed by 14 LED (2 ultraviolet, 4 infrared, 8 white) using an output power of $60 \mathrm{~W}$, a wave length of $495 \mathrm{~nm}$ and a light intensity of 30.000 Mw (Fig. 3).

In the other 9 patients the bleaching agent activation was performed using a Laser diode lamp (G8 D.L., Galbiati) (Fig. 4). 


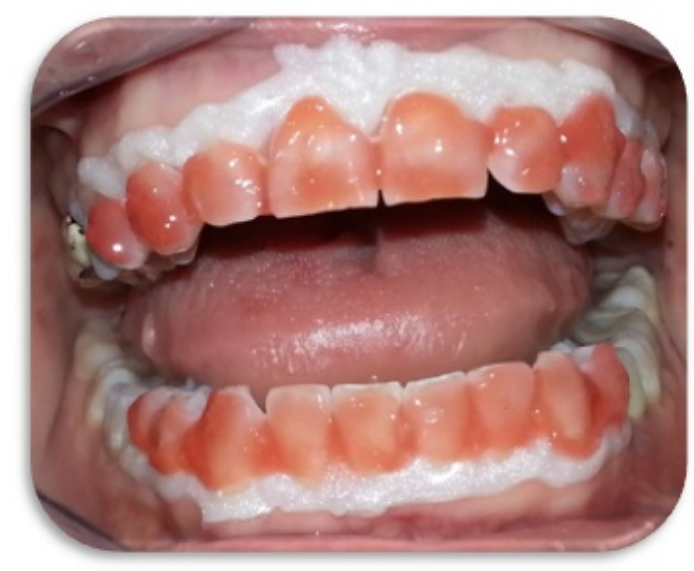

Fig. (2). Clinical phase: application of the bleaching agent on the teeth.

Both groups were subjected to 3 bleaching cycle of $15^{\prime}$ each

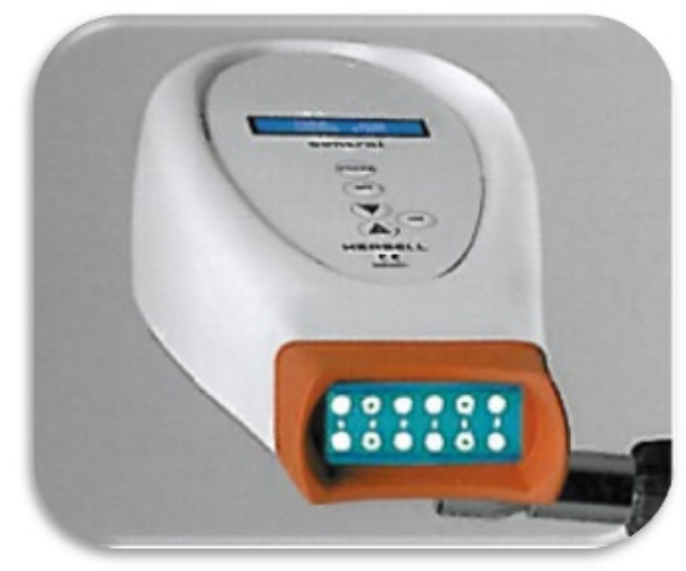

Fig. (3). LED lamp used on 9 patients to activate the bleaching agent applied for 3 bleaching cycle of 15' each.

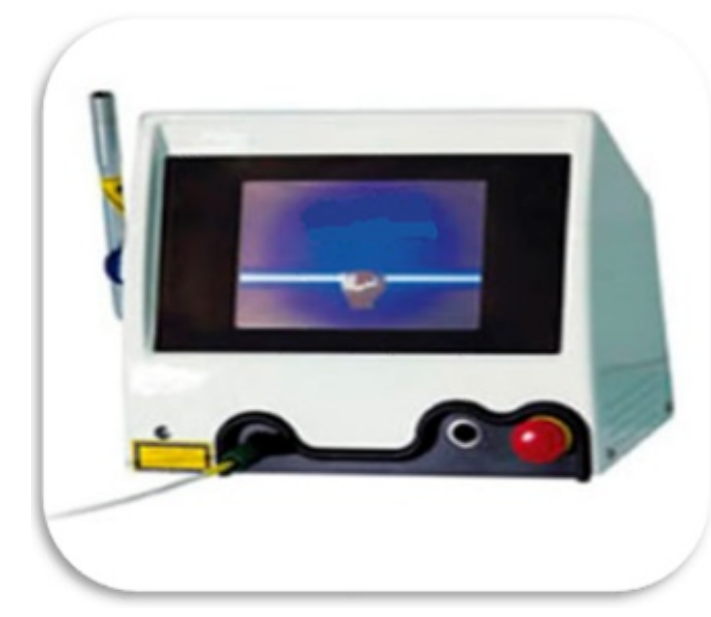

Fig. (4). Laser Diode lamp used on 9 patients to activate the bleaching agent applied for 3 bleaching cycle of $15^{\prime}$ each.

After the bleaching treatment the patients underwent to the color measurements.

The effectiveness of tooth bleaching, indicated by the color difference between the pre treatment and the post treatment condition, was expressed by the values of $\Delta \mathrm{E}$. 
The this variation was determined from the average values of L-lightness (brightness or value), C-chroma (saturation or chroma), H-hue (hue, or tint). The calculation used for this determination was proposed in 1976 by Commission Internationale d'Eclairage and represents a color space closer to clinical reality.

The chromatic evaluations were performed before the treatment and one week after, using a chromatic scale (Vita $\left.\operatorname{Lumin}^{\mathrm{TM}}\right)$ and a spectrophotometer (Spectro shade $\left.{ }^{\mathrm{TM}}\right)($ Figs 5, 6).

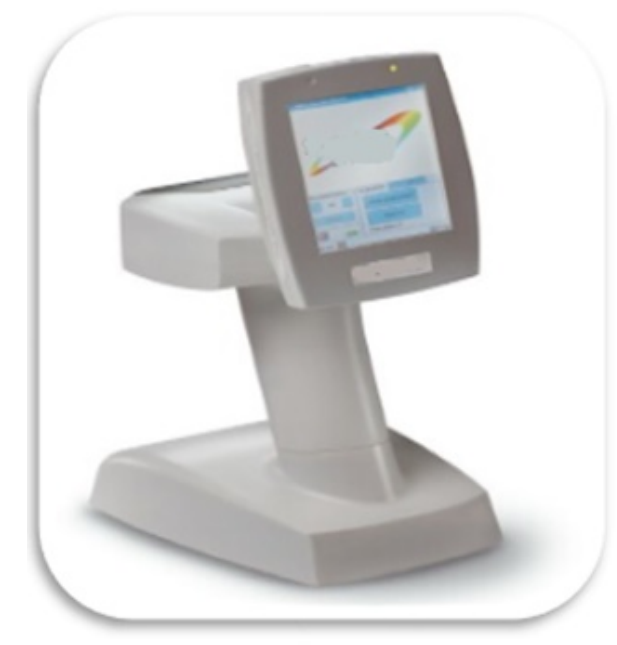

Fig. (5). Chromatic evaluation performed using a spectrophotometer.

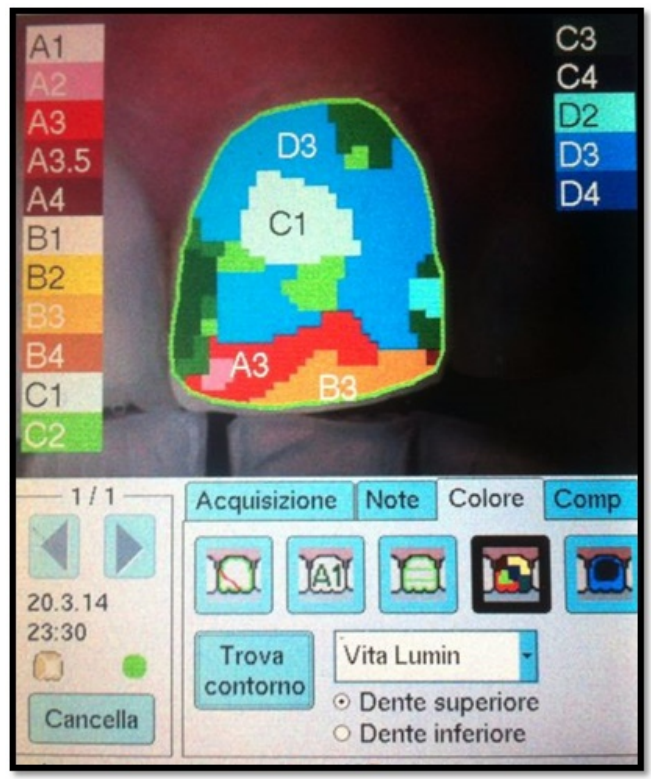

Fig. (6). A chromatic scale that evaluates and compares L-lightness (brightness or value), C-chroma (saturation or chroma), H-hue (hue, or tint) parameters.

The colorimetric scale evaluation, was always performed at the central point of the crowns in the same environment with the same lighting conditions.

3 measurements were done on each teeth to standardize the results lectures and prevent lecture errors, and a mean of the so obtained value was done.

This values were converted in numeric code using the conversion table proposed by Brenna [19] (Table 2).

In the spectrophotometric evaluation the color differences were expressed using the CIELAB (Commission Internationale de l'Èclairage) color coordinates, and color difference $\Delta \mathrm{E}$. 
Table 2. Conversion table (By Brenna F et Al.)

\begin{tabular}{|c|c|c|c|c|c|c|c|c|c|c|c|c|c|c|c|}
\hline B1 & A1 & B2 & D2 & A2 & C1 & C2 & D3 & A3 & C4 & B3 & A3,5 & B4 & C3 & A4 & D4 \\
\hline 16 & 15 & 14 & 13 & 12 & 11 & 10 & 9 & 8 & 7 & 6 & 5 & 4 & 3 & 2 & 1 \\
\hline
\end{tabular}

The $\Delta \mathrm{E}$ values obtained for the single teeth, are the mean of the values obtained from the single different areas of the spectrophotometer scan, converted in numeric values using the Brenna's conversion table.

For $\Delta \mathrm{E}>3$ the easy to detect color differences, was considered clinically significant;

for $2<\Delta \mathrm{E}<3$ the color differences are present but not so well evident;

for $\Delta \mathrm{E}<2$ the color variation was considered negative due to the impossibility for the human eye to detect the color change.

The mean value of pre, post bleaching and follow-up were analyzed using a T-test, with results statistically significant for $\mathrm{P}<0,05$ (Table 3).

\section{RESULTS}

Results showed that the variations in brightness, chroma and hue are significantly influenced by the interaction between the whitening agent and the original colour of the teeth.

The mean results show how in the pre-bleaching LED lamp group, value of 6,22 $\pm 1,64$ raise to $10,33 \pm 2,64$ in the post-bleaching evaluation; while the value of the laser photoactivated group goes from $6 \pm 2,17$ up to $10,88 \pm 2,31$.

The spectrophotometer evaluation confirms the Vita Lumin score, showing within the LED lamp photoactivated group a pre-bleaching mean value of $6 \pm 1,56$ that goes up to $10,5 \pm 2,72$ and within the laser photoactivated group a prebleaching mean value of $5,7 \pm 2,04$ that goes up to $11 \pm 2,42$. Laser-activation has marginally improved the bleaching effectiveness (Table 3).

Table 3. Chromatic evaluation pre and post bleaching ( Mean values, standard deviation, mean differences, $P$. value).

\begin{tabular}{|c|c|c|c|c|c|c|c|c|}
\hline & \multicolumn{4}{|c|}{ CHROMATICA SCALE VALUE } & \multicolumn{4}{|c|}{$\triangle \mathrm{DE}$ SPECTROPHOTOMETER } \\
\hline & \multicolumn{2}{|c|}{$\begin{array}{c}\text { LED LAMP } \\
\text { PHOTO ACTIVATION }\end{array}$} & \multicolumn{2}{|c|}{$\begin{array}{c}\text { LASER } \\
\text { PHOTOATIVATION }\end{array}$} & \multicolumn{2}{|c|}{ LED LAMP PHOTO ACTIVATION } & \multicolumn{2}{|c|}{ LASER PHOTO ACTIVATION } \\
\hline & Pre-bleaching & $\begin{array}{c}\text { Post } \\
\text { bleaching }\end{array}$ & Pre bleaching & Pre-bleaching & Post-bleaching & Pre-bleaching & Post-bleaching & Post-bleaching \\
\hline Mean & 6.22 & 10.33 & 6 & 10.88 & 6 & 10,5 & 5,7 & 11 \\
\hline STD,ERROR & 1,64 & 2,64 & 2,17 & 2,31 & 1,56 & 2,72 & 2,04 & 2,42 \\
\hline DIFFERENCE & \multicolumn{2}{|c|}{4,11} & \multicolumn{2}{|c|}{4,88} & \multicolumn{2}{|c|}{4,5} & \multicolumn{2}{|c|}{5,3} \\
\hline PVALUE & \multicolumn{2}{|c|}{0,00059} & \multicolumn{2}{|c|}{0,00014} & \multicolumn{2}{|c|}{0,0006} & \multicolumn{2}{|c|}{0,00017} \\
\hline
\end{tabular}

All patients treated with laser activation complained an increase in dental sensitivity. This clinical outcome is linked to an increase of the internal temperature of the pulp chamber but compatible with a healthy status of the pulp [17].

\section{DISCUSSION}

A correct color measurement of natural teeth is mandatory for improving color reproduction. The evaluation of the natural teeth color could be performed either by visual or instrumental color analysis. Visual matching is affected by many factors such as illumination and human physiological variabilities, while spectrophotometer is more efficient to provide both systematic and precise measurements of tooth color.

Especially in cosmetic dentistry procedures such as the bleaching technique, is mandatory to have a precise evaluation of teeth color to estimate the success of the procedure.

The bleaching effect achievable using "laser" is realized due to a chemical oxidation process. When the laser energy is applied, hydrogen peroxide $\left(\mathrm{H}_{2} \mathrm{O}_{2}\right)$ splits into a molecule of water $\left(\mathrm{H}_{2} \mathrm{O}\right)$ and an oxygen free radical capable of combining with the molecules of the pigmenting substance, removing them [20].

Our study has evaluated the real efficiency of teeth whitening performed with bleaching agent composed of hydrogen peroxide at $35 \%$ and carbamide peroxide at $10 \%$ with LED activation compared to the laser activation. To avoid the inclusion of excessive variables in this study, the whitening effect determined by two different methods was 
evaluated with measurements pre and post-bleaching.

The analysis considered hue and chroma parameters as targets for determining the color of the dental element (Eclairage International Commission) that resulted from reflection of light on an object and allow the quantitative evaluation of the color change obtained by the treatment [21].

In accordance with Guan [22] which analyzed the sensitivity and the precision of the approach for the evaluation of color variations, two systems of measurement were used: 1) Via a visual chromatic scale (Vita Lumin ${ }^{\mathrm{TM}}$ ), 2) An electronic analyzer of the tooth color (Spectro shade ${ }^{\mathrm{TM}}$ ).

These two approaches have a good correlation, although spectrophotometric analysis underestimates the whiteness index value of CIE, and the measurements following the VITA Lumin are subject to variations related to the sensitivity of the operator [22, 23]. Furthermore, the spectrometer allows the $\Delta \mathrm{E}$ determination, the parameter which confirms the efficiency of the treatment. The data obtained with the color scale were obtained by converting the alphanumeric codes of colors in numbers to make possible a statistical validation [24].

The objective evaluation obtained by the spectrophotometer and color scale measurements showed a real effectiveness of bleaching system used on discolored teeth.

The positive change of color in the teeth treated with laser activation was evident both in the values detected by the spectrophotometer than those recorded on the color scale, this result was evaluated in the gingival third of the crown or in the elements with a higher chroma value [25].

The comparative evaluation between the group of patients undergoing both LED and laser activation is statistically significant [26]. Although the post bleaching evaluation showed an improvement in both groups, these color variations are not always visible to the naked eye [27].

The human eye is not able to evaluate the difference between a bleached tooth with or without laser activation if the $\Delta \mathrm{E}$ value is less than 2 and it isn't able to detect the differences of refraction that can be observed in the various thirds of the crown (incisal, middle and cervical) [28].

The most important difference of the bleaching efficacy in the third gingival than incisal one, is related to the reduced surface, to the small thickness of the enamel-dentin layer and unfavorable light incidence on the incisal region $[29,30]$. Consequently, variations in the cervical layer are the most evident for the observer.

Our study showed how the use of laser activation for whitening procedures increased marginally the efficacy of the bleaching agent if compared to LED lamp photoactivation, but due to the increasing pulp chamber temperature the laser activation lead to an increased dental sensivity.

\section{CONCLUSION}

The results of this study show a marginal efficacy of the use of laser-activating systems associated with bleaching agents in the treatment of teeth whitening.

\section{CONFLICT OF INTEREST}

The authors confirm that this article content has no conflict of interest.

\section{ACKNOWLEDGEMENTS}

Declared none.

\section{REFERENCES}

[1] Maspero C, Giannini L, Carletti V, Farronato G. Sbiancamento dentale: stato dell'arte. Il Dentista Moderno 2008; 4: 52-64.

[2] Cicciù M, Cervino G, Bramanti E. FEM Analysis of Mandibular Prosthetic Overdenture Supported by Dental Implants: Evaluation of Different Retention Methods. Comput Math Methods Med 2015. 2015: 943839

[3] Cicciu M, Bramanti E, Matacena G, Guglielmino E, Risitano G. FEM evaluation of cemented-retained versus screw-retained dental implant single-tooth crown prosthesis. Int J Clin Exp Med 2014; 15(7(4)): 817-25.

[4] Cicciù M, Risitano G, Maiorana C, Franceschini G. Parametric analysis of the strength in the "Toronto" osseous-prosthesis system. Minerva Stomatol 2009; 58(1-2): 9-23.

[PMID: 19234433] 
[5] Horn DJ, Bulan-Brady J, Hicks ML. Sphere spectrophotometer versus human evaluation of tooth shade. J Endod 1998; 24(12): 786-90. [http://dx.doi.org/10.1016/S0099-2399(98)80002-2] [PMID: 10023254]

[6] Lo Giudice G, Lo Giudice A, Isola G, et al. Evaluation of bond strength and detachment interface distribution of different bracket base designs. Acta Med Mediter 2015; 31: 431-6.

[7] Amato M, Scaravilli MS, Farella M, Riccitiello F. Bleaching teeth treated endodontically: long-term evaluation of a case series. J Endod 2006; 32(4): 376-8.

[http://dx.doi.org/10.1016/j.joen.2005.08.018] [PMID: 16554217]

[8] Portelli M, Matarese G, Militi A, Logiudice G, Nucera R, Lucchese A. Temporomandibular joint involvement in a cohort of patients with Juvenile Idiopatic Arthritis and evaluation of the effect induced by functional orthodontic appliance: clinical and radiographic investigation. Eur J Paediatr Dent 2014; 15(1): 63-6. [PMID: 24745596]

[9] Cicciù M, Risitano G, Lo Giudice G, Bramanti E. Periodontal health and caries prevalence evaluation in patients affected by Parkinson's disease. Parkinson's Dis 2012. 2012: 541908

[10] Perdigão J, Baratieri LN, Arcari GM. Contemporary trends and techniques in tooth whitening: a review. Pract Proced Aesthet Dent 2004; 16(3): 185-92.

[PMID: 15199693]

[11] De Moor Roeland JG, Verheyen J, Diachuk A. Insight in the Chemistry of Laser-Activated Dental Bleaching. Scientific World J 2015. 2015: 650492 .

[12] Mohammadi Z, Giardino L, Palazzi F, et al. Effect of Sodium Hypochlorite on the Substantivity of Chlorhexidine. Int J Clin Dent 2013; 6(2): 173-8.

[13] Flynn J, Galloway R, Orchardson R. The incidence of 'hypersensitive' teeth in the West of Scotland. J Dent 1985; 13(3): 230-6. [http://dx.doi.org/10.1016/0300-5712(85)90004-1] [PMID: 3862690]

[14] Lo Giudice G, Lipari F, Lizio A, Cervino G, Cicciù M. Tooth fragment reattachment technique on a pluri traumatized tooth. J Conserv Dent 2012; 15(1): 80-3.

[http://dx.doi.org/10.4103/0972-0707.92613] [PMID: 22368342]

[15] Kawamoto K, Tsujimoto Y. Effects of the hydroxyl radical and hydrogen peroxide on tooth bleaching. J Endod 2004; 30(1): 45-50. [http://dx.doi.org/10.1097/00004770-200401000-00010] [PMID: 14760908]

[16] Basting RT, Amaral FL, França FM, Flório FM. Clinical comparative study of the effectiveness of and tooth sensitivity to 10\% and 20\% carbamide peroxide home-use and 35\% and 38\% hydrogen peroxide in-office bleaching materials containing desensitizing agents. Oper Dent 2012; 37(5): 464-73.

[http://dx.doi.org/10.2341/11-337-C] [PMID: 22616927]

[17] Lo Giudice G, Centofanti A, Artemisia A. Dentin morphology of root canal surface: a SEM study. Biomed Res Int 2015. 2015: 164065

[18] De Moor RJ, Verheyen J, Verheyen P, et al. Laser teeth bleaching: evaluation of eventual side effects on enamel and the pulp and the efficiency in vitro and in vivo. Scie World J 2015; 2015: 835405. [http://dx.doi.org/10.1155/2015/835405] [PMID: 25874258]

[19] Brenna F, Giani S, Striuli S, Tagliabue A. Sbiancamento professionale: luce-assistito contro le tecniche tradizionali. Il Dentista Moderno 2007; 4: 36-62.

[20] Mohammadi Z, Palazzi F, Giardino L. Laser application in tooth bleaching: an update review. Minerva Stomatol 2011; 60(4): 167-78. [PMID: 21471940]

[21] Spagnuolo G, Ametrano G, D'Antò V, et al. Microcomputed tomography analysis of mesiobuccal orifices and major apical foramen in first maxillary molars. Open Dent J 2012; 6: 118-25. [http://dx.doi.org/10.2174/1874210601206010118] [PMID: 22905069]

[22] Guan YH, Lath DL, Lilley TH, Willmot DR, Marlow I, Brook AH. The measurement of tooth whiteness by image analysis and spectrophotometry: a comparison. J Oral Rehabil 2005; 32(1): 7-15. [http://dx.doi.org/10.1111/j.1365-2842.2004.01340.x] [PMID: 15634295]

[23] Horn DJ, Bulan-Brady J, Hicks ML. Sphere spectrophotometer versus human evaluation of tooth shade. J Endod 1998; 24(12): 786-90. [http://dx.doi.org/10.1016/S0099-2399(98)80002-2] [PMID: 10023254]

[24] Knösel M, Reus M, Rosenberger A, Attin T, Ziebolz D. Durability of bleaching results achieved with $15 \%$ carbamide peroxide and 38\% hydrogen peroxide in vitro. Eur J Esthet Dent 2011; 6(3): 342-56. [PMID: 21876869]

[25] Spagnuolo G, Ametrano G, D'Antò V, et al. Effect of autoclaving on the surfaces of TiN -coated and conventional nickel-titanium rotary instruments. Int Endod J 2012; 45(12): 1148-55. [http://dx.doi.org/10.1111/j.1365-2591.2012.02088.x] [PMID: 22757632]

[26] Lunardi N, Correr AB, Rastelli AN, Lima DA, Consani RL. Spectrophotometric evaluation of dental bleaching under orthodontic bracket in enamel and dentin. J Clin Exp Dent 2014; 6(4): e321-6. [http://dx.doi.org/10.4317/jced.51168] [PMID: 25593650] 
[27] Riccitiello F, Maddaloni G, D'Ambrosio C, Amato M, Rengo S, Simeone M. Operating microscope: Diffusion and limits. G Ital Endod 2012; 26(2): 67-72.

[http://dx.doi.org/10.1016/j.gien.2012.05.002]

[28] Spagnuolo G, Desiderio C, Rivieccio V, et al. In vitro cellular detoxification of triethylene glycol dimethacrylate by adduct formation with Nacetylcysteine. Dent Mater 2013; 29(8): e153-60.

[http://dx.doi.org/10.1016/j.dental.2013.04.023] [PMID: 23764026]

[29] Lo Giudice G, Cicciù M, Cervino G, Lizio A, Visco AM. Flowable resin and marginal gap on tooth third medial cavity involving enamel and radicular cementum: a SEM evaluation of two restoration techniques. Indian J Dent Res 2012; 23(6): 763-9. [http://dx.doi.org/10.4103/0970-9290.111256] [PMID: 23649060]

[30] Lo Giudice G, Lo Giudice R, Matarese G, et al. Evaluation of magnification systems in restorative dentistry. An in-vitro study. Dent Cadmos 2015; 83(5): 296-305.

[http://dx.doi.org/10.1016/S0011-8524(15)30036-2]

(C) Lo Giudice et al; Licensee Bentham Open.

This is an open access article licensed under the terms of the Creative Commons Attribution-Non-Commercial 4.0 International Public License (CC BY-NC 4.0) (https://creativecommons.org/licenses/by-nc/4.0/legalcode), which permits unrestricted, non-commercial use, distribution and reproduction in any medium, provided the work is properly cited. 